American Journal of Infectious Diseases 2 (2): 90-97, 2006

ISSN 1553-6203

(C) 2006 Science Publications

\title{
Neuropsychological Consequences of HIV and Drug Ause
}

\author{
${ }^{1}$ Arun Venkatesan, ${ }^{1}$ Ola Selnes, ${ }^{2}$ Valerie Wojna, ${ }^{1}$ Justin C McArthur and ${ }^{1}$ Avindra Nath \\ ${ }^{1}$ Department of Neurology, Johns Hopkins University, Baltimore \\ ${ }^{2}$ Department of Internal Medicine, Section of Neurology, University of Puerto Rico, San Juan, PR
}

\begin{abstract}
Accurate assessment of the functional consequences of human immunodeficiency virus (HIV) infection and drugs of abuse are critical as large populations are afflicted with both. Both are interdependent epidemics with important socioeconomic consequences. Experimental studies in animal models and in vitro clearly indicate that HIV and drugs of abuse cause increased neurodegeneration, glial cell activation and enhanced HIV replication. Nevertheless, most epidemiological studies and neurocognitive studies from the pre-HAART era failed to show any evidence of combined effects of HIV and drugs of abuse. However, these studies provided valuable insight into potential confounding factors in the study of these populations and helped identify sensitive neurocognitive tests for this population. Recent studies show that there is a clear additive effect of the infection and several of the drugs of abuse, although each of the drugs of abuse may have different types of effects on the brain. We propose that future studies should identify neuroimaging and biological surrogate markers to monitor these populations and we discuss therapeutic strategies simultaneously aimed at treating drug addiction and providing neuroprotection.
\end{abstract}

Key words: HIV, dementia, drug abuse, neuropsychology, cognition, addiction

\section{INTRODUCTION}

HIV infection and drug abuse are interlinked epidemics in the United States and in many other countries. In the United States, $36 \%$ of injection drug users are HIV seropositive and nearly $57 \%$ of HIV infected women contract the infection through intravenous drug use ${ }^{[1]}$. Both HIV infection and most drugs of abuse have been shown to cause neurocognitive and behavioral deficits. Hence, it is imperative that we develop a more thorough understanding of their combined or possibly synergistic effects on the brain. This is of great consequence as the HIV infected population is aging and comorbidity factors such as depressive symptoms, alcohol abuse and drug abuse tend to increase with age in HIV seropositive subjects in contrast to HIV seronegative subjects $^{[2]}$, putting the former at greater risk for neurocognitive and behavioral complications.

Intravenous drug abusers with HIV infection appear to develop an especially severe form of HIV encephalitis ${ }^{[4]}$. In addition, they have more severe neuronal damage and loss in the dopaminergic substantia nigra than HIV patients with no history of drug abuse $\mathrm{e}^{[3]}$. They have more activated microglia, particularly in the thalamus, compared to non-drug abusing HIV seropositive patients ${ }^{[5,6]}$ and more GFAPpositive reactive astrocytes in both grey and white matter, compared to HIV negative drug users or HIV seropositive drug users without HIV encephalitis ${ }^{[7]}$. Numerous in vitro studies have shown a synergistic effect of drugs of abuse on the neuropathogenesis of HIV infection, including increased neurotoxicity and increased HIV replication in susceptible cells (reviewed $\left.i^{[8]}\right)$. Despite overwhelming experimental evidence for the detrimental effects of the combined effects of HIV and drugs of abuse on the brain, clinical studies have shown mixed results. In this review, we have critically analyzed each of the clinical studies and tried to determine the reasons for these discrepancies. We further discuss the challenges faced by researchers in studying these cohorts and offer suggestions for the future design of these studies.

Studies that have failed to show an additive effect of drug use on the progression of neuropsychological effects of HIV infection:

A number of cross-sectional and longitudinal studies performed in the pre-HAART era failed to show an effect of drug abuse in HIV infected patients. Results of these studies, in addition to potential confounding factors that may have prevented the detection of combined effects of HIV and drug abuse on neuropsychological function, are discussed below.

In the only study that addressed the incidence of HIV dementia among drug abusers, 6\% (26 out of 404) of patients in the Edinburgh cohort of HIV-positive intravenous drug users developed HIV-1-associated dementia in the 10 years following infection and seroconversion $^{[9]}$. Thus the incidence of dementia was

Corresponding Author: Avindra Nath MD, 600 N. Wolfe St, Path 509, Baltimore, MD 21287, Tel: 443-287-4656, Fax: 410-502-8075 
comparable to that in non-drug abusing HIV infected patients.

In a cross sectional study to examine the neuropsychiatric effects of infection with HIV, 220 drug users (27 HIV negative, 193 HIV positive) were evaluated for premorbid intelligence, memory, nonverbal performance, information processing speed and mood. No evidence of increasing impairment of cognitive function was found with increasing severity of HIV illness, as defined by clinical staging. In addition, HIV-positive patients were not more impaired than a control group of seronegative drug users ${ }^{[10]}$. In another cross sectional study conducted in Baltimore, Maryland a group of 109 HIV seropositive and 51 seronegative intravenous drug users were evaluated for the presence of HIV-1-related neurologic disease using clinical, neurologic, neuropsychological and electrophysiologic evaluations. CD4 cell counts were less than $500 / \mathrm{mm}^{3}$ among $56 \%$ of seropositive participants. Participants from both serologic groups scored significantly lower on neuropsychological tests as compared with norms established for a cohort of homosexual men and there was no clear association between HIV-1 serostatus and performance on these tests $^{[11]}$. Between 1988 and 1990, the same research group studied 151 participants from the AIDS Link to Intravenous Experience (ALIVE) Study and evaluated them neuropsychologically on a semiannual basis. After adjustment for age, education, practice effect and frequency of drug use, neuropsychological performance over time did not vary by HIV-1 serostatus. Overall, after acutely intoxicated individuals were excluded, neither frequency of drug and alcohol use nor HIV-1 seropositivity significantly influenced neuropsychological test performance over a 1-year period $^{[12]}$. This group also performed a cross-sectional comparison of the baseline neuropsychological performance of 107 injecting drug users and 230 homosexual men participating in two longitudinal studies. Age and IQ score rather than risk group accounted primarily for the differences in the cognitive performance, regardless of serostatus and CD4 cell count $^{[13]}$. In another cohort of 185 HIV-infected injection drug users and seronegative controls who were assessed with semiannual neuropsychological assessments for up to 4.5 years there was no evidence to suggest that HIV infection in the context of chronic drug and alcohol use significantly altered the frequency or rate of progression of cognitive symptoms ${ }^{[14]}$. An Italian study compared the performance of three groups of chronic intravenous drug abusers (HIV negative, asymptomatic HIV positive, AIDS) on a battery of neuropsychological tests. While the AIDS group was significantly impaired, no difference was found between HIV negative and HIV positive asymptomatic subjects on any measure ${ }^{[17]}$. Overall, these studies suggested that either HIV infection alone or drug abuse alone leads to neurocognitive impairment. A further worsening of neuropsychological function in HIVinfected drug abusers may be masked by the underlying dysfunction caused by either HIV infection or drug abuse. As discussed later, the use of more sensitive neuropsychological tests may be crucial in identifying combined effects of HIV and drug abuse on neuropsychological function.

Since both HIV and drug abuse, in addition to causing cognitive dysfunction, may affect the basal ganglia leading to motor dysfunction [8], other groups have studied measures of motor function in this population. In a study to assess the combined effects of HIV and drug abuse on motor function, 57 HIVpositive individuals who acquired HIV infection via intravenous drug abuser were compared with 57 matched HIV-positive homosexuals and 98 HIVnegative controls. Parameters analyzed included the magnitude of postural tremor, most rapid voluntary alternating index finger movements and the rise time of most rapid index finger extensions. Although minor deficits were noted in the HIV infected patients, no differences were found between the HIV infected drug and non drug abusers ${ }^{[20]}$. In another study of 99 HIVnegative (62 men and 37 women) and 124 HIV-positive (85 men and 39 women) intravenous drug users from New York the development of clinically significant manifestations in six neurologic domains was assessed over a period of three years. With multivariate adjustment for current and past substance abuse, age, education, and head injury, it was found that extrapyramidal signs and reduced motor ability became increasingly apparent over time in HIV-infected men as their CD4 cell count declined and as the subjects developed the acquired immunodeficiency syndrome. Fewer neurologic signs were seen in the women. The impact of HIV infection among intravenous drug users paralleled that in homosexual men and was independent of alcohol and other drug use ${ }^{[21]}$. These studies, along with several other post-HAART studies discussed in the following section, suggest that although motor dysfunction can occur with HIV infection and with drug abuse, more sensitive parameters of motor dysfunction may need to be used in order to demonstrate combined effects.

Another group, from Austria, examined 42 drugaddicted HIV-1 patients and compared them with a group of 31 seronegative drug addicts as well as with a group of 50 healthy controls using a psychometric test battery and standardized psychiatric scales. They found no significant difference in the degree and frequency of cognitive deficits in the group of HIV-1 patients as compared with the seronegative drug addicts. Elevated scores on the Hamilton depression scale were found in the HIV-1 infected patient group. The authors concluded that chronic drug abuse may contribute as much to cognitive impairment as the HIV-infection itself, but that depression may contribute to abnormalities in neuropsychiaric testing in this 
population ${ }^{[16]}$. In a study from Norway, a battery of neuropsychological tests was administered to detoxified HIV-1 seropositive and seronegative intravenous drug users. Both groups performed below comparable normative levels on the variables studied. The HIV-1 infection per se could not explain the neuropsychological impairment ${ }^{[18]}$. In a subsequent study this group found that anxiety accounted for the incremental impairment in memory observed in HIV infected drug abusers when compared to the uninfected drug users ${ }^{[19]}$. Thus mood alterations in the HIV infected drug abusing populations are common and need to be assessed carefully since they may impact neuropsychological outcomes.

A later study, evaluating patients who presented with prominent psychomotor slowing, found that those with a history of injection drug use had more rapid neurologic progression ${ }^{[15]}$. These studies suggest that in the pre-HAART era, a history of drug use did not substantially alter the neurocognitive presentation of HIV-infection. Nonetheless, it is possible that a subgroup of patients are likely to be more vulnerable to developing neurological abnormalities which may not be detected in large cross-sectional and longitudinal studies.

In a prospective study of $42 \mathrm{HIV}$ seropositive and 39 seronegative intravenous drug abusers matched for age, sex, educational level and pattern of drug abuse, about one-third of both seropositive and seronegative subjects showed slight cognitive deficits at baseline, which did not change during the follow-up period of 12 months ${ }^{[22]}$. This suggests that even in patients who have evidence of baseline neurocognitive impairment, a 12 month period may be insufficient to demonstrate progression of symptoms. It is possible that longer-term studies are necessary to accurately characterize the neurocognitive dysfunction in these patient populations.

Alcohol use is also frequent amongst HIV infected patients. However, at least in one study, it appeared that alcohol use affected neuropsychological performance but did not account for the differences observed in studies of HIV seronegative and seropositive subjects $^{[23]}$. This group later reported that a past history of drug abuse in non-injecting drug users also did not have a significant effect on neurocognitive function ${ }^{[24]}$. Thus alcohol use may be an important confounding factor in these studies.

In a study of non-injection drug users, 51 HIVseronegative participants (21 methamphetaminedependent and 30 non-methadone dependent individuals) were studied. The $52 \mathrm{HIV}$-seropositive participants included 22 methamphetamine-dependent individuals and 30 individuals with no history of methamphetamine dependence. Surprisingly, methamphetamine dependence was associated with basal ganglia and parietal cortex volume increases and in one of these structures-the nucleus accumbens-there appeared to be a larger effect in younger methamphetamine abusers. Interestingly, neurocognitive impairment was associated with decreased cortical volumes in HIV-positive participants but with increased cortical volumes in methamphetamine-dependent participants ${ }^{[25]}$. The biochemical and cellular substrate leading to the increase in volume needs to be determined. This study suggests that if surrogate markers (e.g. neuroradiological findings) are to be used in the study of these patient populations, care must be taken to ensure that these markers are accurate and specific for neurocognitive dysfunction. In addition, close attention must be paid to the types of drugs being abused by the patients since these drugs may have opposing effects on brain cells.

\section{Studies that claim an additive effect of drug abuse on neuropsychological deficits of HIV infection:}

As discussed above, many pre-HAART era studies did not demonstrated enhanced neurocognitive effects resulting from HIV infection and drug abuse. However, several pre-HAART studies along with many studies conducted in the post-HAART era do support the claim that the combination of HIV and drug abuse results in more severe neurocognitive dysfunction.

In one study from the pre-HAART era where 211 subjects were initially evaluated from a methadone program, $70(33 \%)$ were HIV seropositive and 141 (67\%) were seronegative. At baseline, by univariate analysis, the seropositive intravenous drug users were significantly more impaired than seronegatives on 4 of 8 measures: Finger Tapping--dominant hand, Digit Span Forward, Trail making A and WAIS-Similarities. However, by multivariate analysis the seropositives were significantly more impaired only on the WAISSimilarities and Wechsler Paired-Associates Learning tests ${ }^{[26]}$. In another study, 220 methadone-clinic patients without evidence of HIV-related illnesses were given baseline psychological screening tests, as well as serological testing for HIV antibodies. At baseline, 83 (38\%) were HIV seropositive. On initial testing, after controlling for race/ethnicity, age, sex and drug use, the seropositive groups were more cognitively impaired than the seronegatives. The differences were statistically significant for three subtests on univariate analysis: finger tapping (dominant hand), digit span (forward) and similarities ${ }^{[27]}$. Even though these earlier studies were not controlled for factors such as depression and other comorbidities that may affect neuropsychological performance, they suggest that some neurocognitive tests may be more sensitive in demonstrating combined effects of HIV and drug abuse.

More recently, several well-designed studies have demonstrated combined neuropsychiatric effects of HIV and drug abuse. A study from San Diego included 200 participants in 4 groups: HIV infected/ methamphetamine dependent (HIV+/METH+), HIV negative/ methamphetamine dependent (HIV- 
/METH+), HIV infected/ methamphetamine nondependent (HIV+/METH-), and HIV negative/ methamphetamine nondependent (HIV-/METH-). Rates of global neuropsychological impairment were higher in the HIV+/METH+ (58\%), HIV-/METH+ (40\%) and HIV+/METH- (38\%) groups compared to the HIV/METH- (18\%) group. These findings suggest an additive effect of HIV and methamphetamine in causing neuropsychological impairment ${ }^{[37]}$. In another study, recent stimulant (methamphetamine and/or cocaine) use among HIV-infected adults adversely affected sustained attention ${ }^{[31]}$. Combined use of methamphetamine and cocaine has also been reported to cause a more rapid progression of HIV dementia ${ }^{[38]}$. These observations are also supported by a magnetic resonance spectroscopy study of $68 \mathrm{HIV}$ positive patients, 24 with history of chronic methamphetamine use, that showed metabolic abnormalities with chronic methamphetamine use ${ }^{[39]}$.

It is possible that only a subgroup of HIV-infected drug abusers are more prone to the development of increased neurological abnormalities; if so, abnormalities may get diluted in large cross-sectional and longitudinal studies. In a series of 71 consecutive patients diagnosed with HIV-associated dementia over a 10-year period from 1984 to 1994, those with a history of injection drug use and prominent psychomotor slowing had more rapid neurologic progression \{Bouwman, 1998 \#613\}. Co-infection with other viruses may also play an important role in the exacerbation of neuropsychiatric impairment. HIV infected drug abusers are often co-infected with hepatitis $\mathrm{C}$ which may also cause neuropsychiatric impairment ${ }^{[40]}$. For example, the combination of HIV infection, Hepatitis $\mathrm{C}$ virus and methamphetamine has a more detrimental effect in cognitive function most likely due to an additive effect. Patients with these factors present with more severe neuropsychological and psychiatric abnormalities ${ }^{[41]}$, worse global neuropsychological function ${ }^{[42,43]}$ and increased reaction time ${ }^{[44]}$.We anticipate that current and future studies will help to identify subgroups at particular risk for neuropsychiatric complications.

In a small study of $25 \mathrm{HIV}$-seropositive drug users (groups II-III and IV [A, C2 and E] of the CDC classification), subjects were evaluated with the WAIS scale to determine possible involvement of cognitive functions in the not yet overt phases of AIDS. The results were compared with those obtained in two control populations composed of 19 seronegative drug abusers and 24 healthy subjects. The study indicated that drug abuse was the main factor, among those analyzed, associated with a deficit in cognitive functions ${ }^{[28]}$. In two follow up studies the same group concluded that the poor performance of group II-III patients compared to group IV may be explained by secondary factors related to seropositivity (anxiety and panic) rather than the disease itself ${ }^{[29]}$ and that drug use alone was sufficient to cause impairment of neuropsychological performance and failed to demonstrate a direct additive effect of HIV infection ${ }^{[30]}$. Together these studies clearly demonstrate that behavioral abnormalities in HIV infected drug abusers are common and may impact the neuropsychological performance.

Several studies suggest that measurements of reaction time (RT) may be an important and more sensitive discriminating factor in HIV infected drug abusers. In a sample of 23 non-drug users and 17 stimulant users (cocaine and/or methamphetamine), all who were HIV-positive, compared to the non-drug users, stimulant users showed a gradual increase in reaction time variability and omission errors. The groups were equivalent on other measures of attention, global neuropsychological functioning, mood and demographic variables ${ }^{[31]}$. In another study where subjects with a history of intravenous drug abuse (65 seropositive subjects and 49 seronegative controls) were evaluated with a RT test which included one measure of simple RT and three measures of complex RT, the seropositive group performed slower than the control group on two RT tasks. These results suggest that computerized RT measures may be more sensitive than conventional neuropsychological tests in detecting subtle cognitive and motor retardation in the early stages of HIV infection ${ }^{[32]}$. Of note, alcohol consumption can be a significant confounding variable in these studies, since RT is also increased in noninjecting drug users with HIV infection ${ }^{[33]}$. In addition, heavy alcohol consumption causes a synergistic impairment of motor and visuomotor speed in HIV infected patients ${ }^{[34]}$.

In other efforts to find neuropsychological tests that may be sensitive to the combined effects of HIV and drug abuse, an extensive neuropsychological evaluation was performed in $90 \mathrm{HIV}$ infected patients with history of drug abuse and was compared with that of two seronegative control group. One control group of 22 subjects with no history of drug abuse provided a reference of normal neuropsychological performance. The other control group, consisting of 48 seronegative subjects with a history of drug abuse, allowed the differentiation of whether the performance of the seropositive subjects derived from their history of drug abuse. The results indicated that HIV infection in drug users was associated with deficits in attention, verbal and visual memory, verbal skills, concept formation and reasoning, visual-constructive skills, manual dexterity and perceptive-motor speed, which could not be attributed to a history of drug abuse. However, the seronegative drug users also showed some of these alterations, which suggested that seropositivity was not only associated with a decrease in performance in these tasks, but also added to the alterations seen in seronegative subjects as a consequence of drug abuse $^{[35]}$. Another neuropsychological parameter that 
appears to be sensitive to the combined effects of HIV and drug abuse is auditory working memory; a dividedattention test sensitive to subcortical and frontal lobe involvement, was found to be impaired in HIV infected drug users when $41 \mathrm{HIV}$ seropositive and $37 \mathrm{HIV}$ seronegative male drug users were compared ${ }^{[36]}$.

Possible reasons for the discrepancy between in vitro and clinical studies: Our understanding of the confounding factors that may impact studies of neuropsychological function in $\mathrm{HIV}$-infected drug abusers has evolved over the years. While some of these factors have been controlled for in later studies, others are difficult to control. The latter includes duration, dose and mixture of drugs, contaminants in street drugs, irregular and erratic patterns of use, genetics of drug susceptibility, genetics of viral susceptibility, and effects of drugs at different stages of HIV infection. Factors that can be controlled for include low educational background, low motivation for detailed neuropsychological batteries and psychiatric comorbidities which are common in this population. Depression, for example, is common in injecting drug users and although depression contributes to poor neuropsychological performance in intravenous drug users, this effect was not exacerbated by HIV infection ${ }^{[45,46]}$. Sex differences must also be accounted for in studies of the neuropsychiatric effects of HIV and drug abuse; in one study, women reported more depressive symptoms than men and this gender difference was most evident in women who were both infected with HIV and who were also injection drug users $^{[47]}$. Head trauma is another potential confounder, since subtle neurologic and neuropsychological abnormalities in HIV infected intravenous drug users may be more evident in those with head injury ${ }^{[48,49]}$. Other confounding factors include poor medication adherence in drug abusers and in cognitively impaired patients, which is of particular importance in the postHAART era ${ }^{[50]}$. Future studies need to pay close attention to the potential confounding factors that impact neuropsychological assessment in these patients (Table).

The effects of drug abuse seem to be more apparent in later stages of HIV infection and are difficult to demonstrate in the asymptomatic stages of HIV infection when intervention may be most desirable. It is possible that the development of surrogate markers may be useful in these stages. For example, we have found that mildly demented HIV infected drug abusing patients show striking increases in markers of oxidative stress in the CSF (Nath et al., unpublished observations). We believe that the development of reliable biological surrogate markers in CSF or serum for glial and neuronal dysfunction and neuroimaging studies, particularly with novel positron emission tomography ligands that are capable of evaluating the inflammatory pathways and dopaminergic and serotonergic systems, will be essential for monitoring these patients in pathogenesis and treatment studies.

Table: Confounding factors that affect neuropsychological function in HIV infected drug abusers

Age

Educational level

Comorbidities:

Head injury

Depression

Anxiety

Insomnia/sleep deprivation

Other neuropsychiatric illnesses

Hepatitis $\mathrm{C}$ virus infection

Vitamin deficiencies

Low motivation on neuropsychological testing

Poor medication adherence

Contaminants in street drugs

Erratic patterns of drug use

Exposure to multiple drugs of abuse

Host and viral genetics

Therapeutic approaches to HIV infected drug abusing patients: Therapeutic intervention in this population requires strategies that will impact drug dependence and addiction as well as provide neuroprotection. Theoretical considerations and preclinical data suggest a potential role for glutamateinhibiting agents in the treatment of drug addiction. For example, cocaine has been shown to elevate extracellular glutamate levels in various limbic brain areas $^{[51]}$ and glutamate transmission in the nucleus accumbens appears to play an important role in the reinstatement of cocaine self-administration in rats ${ }^{[52]}$. Glutamate antagonists also have neuroprotective properties and therefore are attractive candidates for this patient population. In one study, 18 HIVseropositive cocaine-dependent, opiate-agonist maintained patients received lamotrigine, an indirect glutamate release inhibitor. Subjects receiving standard lamotrigine induction demonstrated a significant decrease in cocaine-positive urine samples, and neuropsychological assessments suggested a decrement in the Trail Making Tests, but no other decreases in cognitive functioning ${ }^{[53]}$. Thus studies of larger sample sizes may be warranted. In a related approach, inhibitors of glutamate carboxypeptidase II (NAALAdase), an enzyme that generates glutamate from a peptide precursor, have been studied. NAALAdase inhibitors prevent both the acquisition and expression of the conditioned place preference in response to cocaine ${ }^{[54]}$. NAALADase inhibition has also been shown to prevent cocaine-kindled seizures ${ }^{[55]}$ and to attenuate the development of cocaine-induced sensitization to the locomotor-activating effects of cocaine in mice ${ }^{[56]}$. These compounds also attenuate morphine tolerance ${ }^{[57]}$ and have neuroprotective properties in a variety of neuronal injury models ${ }^{[58]}$. Further, these compounds can be administered orally and have excellent CNS penetration ${ }^{[59]}$. It will be of 
interest to determine whether inhibitors of NAALADase can accomplish the dual goals of reduction in addictive behavior and neuroprotection in HIV-infected drug abusers.

In summary, the epidemic of HIV-infected drug abusers has immense socioeconomic consequences throughout the United States and the world. Clinical studies to assess neuropsychological functioning in HIV infected drug abusers pose several challenges for researchers. Use of well controlled populations, precise neuropsychological testing with small batteries that are sensitive to the effects of HIV and drug abuse as well as the use of surrogate markers are essential to monitor these populations and to develop strategies for intervention that will impact drug addiction and provide neuroprotection.

\section{REFERENCES}

1. Anonymous, 2002. CDC DoHAP: DrugAssociated HIV Transmission Continues in the United States.

2. Justice, A.C., K.A. McGinnis, J.H. Atkinson,R.K. Heaton, C. Young, J. Sadek, T. Madenwald, J.T Becker, J. Conigliaro and S.T. Brown et al., 2004. Psychiatric and neurocognitive disorders among HIV-positive and negative veterans in care: Veterans Aging Cohort Five-Site Study. Aids, 1: S49-59.

3. Reyes, M.G., F. Faraldi, C.S. Senseng, C. Flowers and R. Fariello, 1991. Nigral degeneration in acquired immune deficiency syndrome (AIDS). Acta Neuropathol 1991, 82:39-44.

4. Bell, J.E, R.P. Brettle, A. Chiswick and P. Simmonds, 1998. HIV encephalitis, proviral load and dementia in drug users and homosexuals with AIDS. Effect of neocortical involvement. Brain, 121: 2043-2052.

5. Arango, J.C., P. Simmonds, R.P. Brettle and J.E. Bell, 2004. Does drug abuse influence the microglial response in AIDS and HIV encephalitis? Aids, 18 (Suppl), 1: S69-74.

6. Tomlinson, G.S., P. Simmonds, A. Busuttil, A. Chiswick and J.E. Bell, 1999. Upregulation of microglia in drug users with and without presymptomatic HIV infection. Neuropathol. Appl. Neurobiol., 25: 369-379.

7. Anderson, C.E., G.S. Tomlinson, B. Pauly, F.W. Brannan, A. Chiswick, R. Brack-Werner, P. Simmonds and J.E. Bell, 2003. Relationship of Nef-positive and GFAP-reactive astrocytes to drug use in early and late HIV infection. Neuropathol. Appl. Neurobiol., 29: 378-388.

8. Nath, A., K.F. Hauser, V. Wojna, R.M. Booze, W. Maragos, M. Prendergast, W. Cass and J.T. Turchan, 2003. Molecular basis for interactions of HIV and drugs of abuse. J. Acquir. Immune. Defic. Syndr., 31 (Suppl. 2): S62-69.
9. Goodwin, G.M., D.O. Pretsell, A. Chiswick, V. Egan and R.P. Brettle, 1996. The Edinburgh cohort of HIV-positive injecting drug users at 10 years after infection: a case-control study of the evolution of dementia. Aids, 10: 431-440.

10. Egan, V., R.P. Brettle and G.M. Goodwin, 1992. The Edinburgh cohort of HIV-positive drug users: Pattern of cognitive impairment in relation to progression of disease. Br. J. Psychiat., 161: 522531.

11. Royal, W. 3rd, M. Updike, O.A. Selnes, T.V. Proctor, L. Nance-Sproson, L. Solomon, D. Vlahov, D.R. Cornblath and J.C. McArthur, 19991. HIV-1 infection and nervous system abnormalities among a cohort of intravenous drug users. Neurology, 41: 1905-1910.

12. Concha, M., N.M. Graham, A. Munoz, D. Vlahov, Wd. Royal, M. Updike, T. Nance-Sproson, O.A. Selnes and J.C. McArthur, 1992. Effect of chronic substance abuse on the neuropsychological performance of intravenous drug users with a high prevalence of HIV-1 seropositivity. Am. J. Epidemiol., 136: 1338-1348.

13. Concha, M., O.A. Selnes, D. Vlahov, T. NanceSproson, M. Updike, W. Royal, J. Palenicek and J.C. McArthur, 1997. Comparison of neuropsychological performance between AIDSfree injecting drug users and homosexual men. Neuroepidemiology, 16: 78-85.

14. Selnes, O.A., N. Galai, J.C. McArthur, S. Cohn, W.3rd Royal, D. Esposito and D. Vlahov, 1997. HIV infection and cognition in intravenous drug users: Long-term follow-up. Neurology, 48: 223230.

15. Bouwman, F.H., R.L. Skolasky, D. Hes, O.A. Selnes, J.D. Glass, T.E. Nance-Sproson, W. Royal, G.J. Dal Pan and J.C. McArthur, 1998. Variable progression of HIV-associated dementia. Neurology, 50: 1814-1820.

16. Pakesch, G., N. Loimer, J. Grunberger, D. Pfersmann, L. Linzmayer and S. Mayerhofer, 1992. Neuropsychological findings and psychiatric symptoms in HIV-1 infected and noninfected drug users. Psychiat. Res., 1992, 41:163-177.

17. Cappa, S.F., T.M. Truong, D. Vangi and L.A. Vignolo, 1992. The neuropsychological consequences of HIV infection in drug addicts. Ital. J. Neurol. Sci., 13: 465-468.

18. Hestad, K., P. Aukrust, B. Ellertsen, H. Klove and K. Wilberg, 1993. Neuropsychological deficits in HIV-1 seropositive and seronegative intravenous drug users. J. Clin. Exp. Neuropsychol., 15: 732742 .

19. Hestad, K., P. Aukrust, B. Ellertsen and H. Klove, 1996. Neuropsychological deficits in HIV-1 seropositive and seronegative intravenous drug users (IVDUs): A follow-up study. J. Intl. Neuropsychol. Soc., 2: 126-133. 
20. von Giesen, H.J., H. Hefter, H. Roick, S. Mauss and G. Arendt, 1994. HIV-specific changes in the motor performance of HIV-positive intravenous drug abusers. J. Neurol., 242: 20-25.

21. Marder, K., X. Liu, Y. Stern, R. Malouf, G. Dooneief, K. Bell, G. Todak, M. Joseph, S. Sorrell, W. el Sadr et al., 1995. Risk of human immunodeficiency virus type 1-related neurologic disease in a cohort of intravenous drug users. Arch. Neurol., 52: 1174-1182.

22. Bono, G., M. Mauri, E. Sinforiani, G. Barbarini, L. Minoli and M. Fea, 1996. Longitudinal neuropsychological evaluation of HIV-infected intravenous drug users. Addiction, 91: 263-268.

23. Bornstein, R.A., R. Fama, P. Rosenberger, C.C. Whitacre, M.F. Para, H.A. Nasrallah and R.J. Fass, 1993. Drug and alcohol use and neuropsychological performance in asymptomatic HIV infection. J. Neuropsychiat. Clin. Neurosci., 5: 254-259.

24. Basso, M.R. and R.A. Bornstein, 2003. Effects of past noninjection drug abuse upon executive function and working memory in HIV infection. J. Clin. Exp. Neuropsychol., 25: 893-903.

25. Jernigan, T.L., A.C. Gamst, S.L. Archibald, C. Fennema-Notestine, M.R. Mindt, T.L. Marcotte, R.K. Heaton, R.J. Ellis and i. Grant, 2005. Effects of methamphetamine dependence and HIV infection on cerebral morphology. Am. J. Psychiat,, 162: 1461-1472.

26. Silberstein, C.H., F.P. McKegney, M.A. O'Dowd, P.A. Selwyn, E. Schoenbaum, E. Drucker, C. Feiner, C.P. Cox and G. Friedland, 1987. A prospective longitudinal study of neuropsychological and psychosocial factors in asymptomatic individuals at risk for HTLVIII/LAV infection in a methadone program: preliminary findings. Intl. J. Neurosci., 32: 669676.

27. McKegney, F.P., M.A. O'Dowd, C. Feiner, P. Selwyn, E. Drucker and G.H. Friedland, 1990. A prospective comparison of neuropsychologic function in HIV-seropositive and seronegative methadone-maintained patients. Aids, 4: 565-569.

28. Grassi, M.P., C. Perin, F. Clerici, C. Zocchetti, A. Cargnel and A. Mangoni, 1993. Neuropsychological performance in HIV-1infected drug abusers. Acta Neurol. Scand., 88: 119-122.

29. Grassi, M.P., C. Perin, F. Clerici, C. Zocchetti, M. Borella, A. Cargnel and A. Mangoni, 1997. Effects of HIV seropositivity and drug abuse on cognitive function. Eur. Neurol., 37: 48-52.

30. Grassi, M.P., F. Clerici, C. Perin, C. Zocchetti, M. Borella, A. Cargnel and A. Mangoni, 1995. HIV infection and drug use: Influence on cognitive function. Aids, 9: 165-170.
31. Levine, A.J., D.J. Hardy, E. Miller, S.A. Castellon, D. Longshore and C.H. Hinkin, 2006. The effect of recent stimulant use on sustained attention in HIVinfected adults. J. Clin. Exp. Neuropsychol., 28: 29-42.

32. Ayuso-Mateos, J.L., M. Pereda, A. Gomez Del Barrio, S. Echevarria, M.C. Farinas and D. GarciaPalomo, 2000. Slowed reaction time in HIV-1seropositive intravenous drug users without AIDS. Eur. Neurol., 44:72-78.

33. Durvasula, R.S., H.F. Myers, P. Satz, E.N. Miller, H. Morgenstern, M.A. Richardson, G. Evans and D. Forney, 2000. HIV-1, cocaine and neuropsychological performance in African American men. J. Intl. Neuropsychol. Soc., 6: 322335.

34. Rothlind, J.C., T.M. Greenfield, A.V. Bruce, D.J. Meyerhoff, D.L. Flenniken, J.A. Lindgren and M.W. Weiner, 2005. Heavy alcohol consumption in individuals with HIV infection: effects on neuropsychological performance. J. Intl. Neuropsychol. Soc., 11: 70-83.

35. Vazquez-Justo, E., M. Rodriguez Alvarez and J. Carro Ramos, 2003. Neuropsychological performance in HIV/AIDS intravenous drug users. J. Clin. Exp. Neuropsychol., 25: 852-865.

36. Martin, E.M., T.S. Sullivan, R.A. Reed, T.A. Fletcher, D.L. Pitrak, W. Weddington and M. Harrow, 2001. Auditory working memory in HIV1 infection. J. Intl. Neuropsychol. Soc., 7: 20-26.

37. Rippeth, J.D., R.K. Heaton, C.L. Carey, T.D. Marcotte, D.J. Moore, R. Gonzalez, T. Wolfson and I. Grant, 2004. Methamphetamine dependence increases risk of neuropsychological impairment in HIV infected persons. J. Intl. Neuropsychol. Soc., 10: $1-14$.

38. Nath, A., W. Maragos, M. Avison, F. Schmitt and J. Berger, 2001. Accelerated HIV dementia with methamphetamine and cocaine use. J. Neurovirol., 7: 66-71.

39. Chang, L., T. Ernst, O. Speck and C.S. Grob, 2005. Additive effects of HIV and chronic methamphetamine use on brain metabolite abnormalities. Am. J. Psychiat., 162: 361-369.

40. Ryan, E.L., S. Morgello, K. Isaacs, M. Naseer and P. Gerits, 2004. Neuropsychiatric impact of hepatitis $\mathrm{C}$ on advanced HIV. Neurology, 62: 957962.

41. Morgello, S., L. Estanislao, E. Ryan, P. Gerits, D. Simpson, S. Verma, A. DiRocco and V. Sharp, 2005. Effects of hepatic function and hepatitis $C$ virus on the nervous system assessment of advanced-stage HIV-infected individuals. Aids, 19 (Suppl 3): S116-122. 
42. Letendre, S.L., M. Cherner, R.J. Ellis, J. MarquieBeck, B. Gragg, T. Marcotte, R.K. Heaton, J.A. McCutchan and I. Grant, 2005. The effects of hepatitis C, HIV and methamphetamine dependence on neuropsychological performance: Biological correlates of disease. Aids, 19 (Suppl. 3): S72-78.

43. Cherner, M., S. Letendre, R.K. Heaton, J. Durelle, J. Marquie-Beck, B. Gragg and I. Grant, 2005. Hepatitis C augments cognitive deficits associated with HIV infection and methamphetamine. Neurology, 64: 1343-1347.

44. Gonzalez, R., J. Jacobus and E.M. Martin, 2005. Investigating neurocognitive features of hepatitis $C$ virus infection in drug users: Potential challenges and lessons learned from the HIV literature. Clin. Infect. Dis., 41 (Suppl. 1): S45-49.

45. Waldrop-Valverde, D., R.L. Ownby and M. Kumar, 2005. Influence of depression and HIV serostatus on the neuropsychological performance of injecting drug users. Psychiat. Clin. Neurosci., 59: 372-378.

46. Vazquez-Justo, E., M. Rodriguez Alvarez and M.J. Ferraces Otero, 2003. Influence of depressed mood on neuropsychologic performance in HIVseropositive drug users. Psychiat. Clin. Neurosci., 57: 251-258.

47. Wisniewski, A.B., S. Apel, O.A. Selnes, A. Nath, J.C. McArthur and A.S. Dobs, 2005. Depressive symptoms, quality of life and neuropsychological performance in HIV/AIDS: the impact of gender and injection drug use. J. Neurovirol., 11: 138-143.

48. Marder, K., Y. Stern, R. Malouf, M.X. Tang, K. Bell, G. Dooneief, W. el-Sadr, S. Goldstein, J. Gorman and M. Richards et al., 1992. Neurologic and neuropsychological manifestations of human immunodeficiency virus infection in intravenous drug users without acquired immunodeficiency syndrome. Relationship to head injury. Arch. Neurol., 49: 1169-1175.

49. Hestad, K., M. Updike, O.A. Selnes and W.3rd Royal, 1995. Cognitive sequelae of repeated head injury in a population of intravenous drug users. Scand. J. Psychol., 36: 246-255.

50. Hinkin, C.H., D.J. Hardy, K.I. Mason, S.A. Castellon, R.S. Durvasula, M.N. Lam and M. Stefaniak, 2004. Medication adherence in HIVinfected adults: effect of patient age, cognitive status and substance abuse. Aids, 18 (Suppl. 1): S19-25.
51. Smith, J.A., Q. Mo, H. Guo, P.M. Kunko and S.E. Robinson, 1995. Cocaine increases extraneuronal levels of aspartate and glutamate in the nucleus accumbens. Brain Res., 683: 264-269.

52. Cornish, J.L. and P.W. Kalivas, 2000. Glutamate transmission in the nucleus accumbens mediates relapse in cocaine addiction. J. Neurosci., 20: RC89.

53. Margolin, A., S.K. Avants, D. DePhilippis and T.R. Kosten, 1998. A preliminary investigation of lamotrigine for cocaine abuse in HIV-seropositive patients. Am. J. Drug Alcohol Abuse, 24: 85-101.

54. Slusher, B.S., A. Thomas, M. Paul, C.A. Schad and C.R.Jr. Ashby, 2001. Expression and acquisition of the conditioned place preference response to cocaine in rats is blocked by selective inhibitors of the enzyme N-acetylated-alpha-linked-acidic dipeptidase (NAALADASE). Synapse, 41: 22-28.

55. Witkin, J.M., M. Gasior, C. Schad, A. Zapata, T. Shippenberg, T. Hartman and B.S. Slusher, 2002. NAALADase (GCP II) inhibition prevents cocainekindled seizures. Neuropharmacology, 43: 348356.

56. Shippenberg, T.S., W. Rea and B.S. Slusher, 2000. Modulation of behavioral sensitization to cocaine by NAALADase inhibition. Synapse, 38: 161-166.

57 Kozela, E., M. Wrobel, T. Kos, J. Wojcikowski, W.A. Daniel, K.M. Wozniak, B.S. Slushe and P. Popik, 2005. 2-MPPA, a selective glutamate carboxypeptidase II inhibitor, attenuates morphine tolerance but not dependence in $\mathrm{C} 57 / \mathrm{Bl}$ mice. Psychopharmacology (Berl), 183: 275-284.

58 Bacich, D.J., K.M. Wozniak, X.C. Lu, D.S. O'Keefe, N. Callizot, W.D. Heston and B.S. Slusher, 2005. Mice lacking glutamate carboxypeptidase II are protected from peripheral neuropathy and ischemic brain injury. $\mathrm{J}$. Neurochem., 95: 314-323.

59. van der Post, J.P., S.J. de Visser, M.L. de Kam, M. Woelfler, D.C. Hilt, J. Vornov, E.S. Burak, E. Bortey, B.S. Slusher and T. Limsakun et al., 2005. The central nervous system effects, pharmacokinetics and safety of the NAALADaseinhibitor GPI 5693. Br. J. Clin. Pharmacol., 60: 128-136. 